\title{
Research on the Application of the Standard Operating Procedure in Military Financial Management
}

\author{
Kaiyang Xu \\ Training Team 28, Graduate Management Department \\ Logistics University of PAP \\ Tianjin, China \\ fabulous0134YY0o@163.com
}

\begin{abstract}
The Standard Operating Procedure (SOP) is a highly efficient work flow summarized by the internal managers of an organization after years of practice, serving as a work rule within a department. The application of the SOP to military financial management will play a positive role in improving the quality and efficiency of financial management, optimizing the internal work structure of an organization, perfecting the relevant work flow and preventing financial work risks. The paper consists of five parts. Firstly, the basic background of the SOP is introduced. Secondly, the necessity of applying the Standard Operating Procedure to advance the standardized management of military finance is analyzed from the aspects of improving the quality and efficiency of military financial work, relieving the contradiction between the increasingly heavy financial task and the relative shortage of high-quality financial personnel, preventing financial work risks, and providing the basis for the comprehensive evaluation of standardized management of financial business. Thirdly, the conception of applying the Standard Operating Procedure to military financial management is put forward. Fourthly, problems that should be paid attention to in the application of the Standard Operating Procedure in military finance such as dealing properly with the relationship between compliance with laws and regulations and applicability, balancing between standardized execution and flexible management and laying emphasis on the regular reformulation of the Standard Operating Procedure are analyzed. Fifthly, the conclusion of the paper is reached.
\end{abstract}

Keywords-the Standard Operating Procedure (SOP); military finance; financial management

\section{INTRODUCTION}

The SOP, which sprang up in the 18th Century and has been developed maturely in modern times, is a kind of management method which is widely used. Appling the SOP to military financial management helps to renew ideas, promote the standardization and scientification of financial management, and promote the improvement of military economic benefits [1]

\section{THE NECESSITY OF APPLYING THE STANDARD OPERATING PROCEDURE (SOP) TO ADVANCE THE STANDARDIZED MANAGEMENT OF MILITARY FINANCE}

\section{A. Improving the Quality and Efficiency of Military} Financial Work

At present, the standardized management of military finance has made great progress. With various regulations and policies been introduced and all kinds of standards and systems been formulated in succession, the laws and regulations system has been initially established, with a wide coverage and a strong guidance. But it is undeniable that some rules and regulations are too macro to operate. Financial workers find it hard to hold the scale and deviation may be produced easily. With the unsatisfying performance of some departments in carrying out the collective financial management system of the Party committee, the weak power of financial supervision, and the speculative behavior of some individual personnel driven by the interests, the quality and efficiency of military financial work are influenced significantly [2]. The establishment of a perfect military financial Standard Operating Procedure can solve the problem of the effective connection between laws and regulations and financial work well, and make up for the "gap" between regulations and actual operation so as to reduce executive deviation.

B. Relieving the Contradiction Between the Increasingly Heavy Financial Task and the Relative Shortage of HighQuality Financial Personnel

With the continuous advancement of military modernized construction, the logistic support work has been improved and developed day by day and the workload of the financial department is increasing gradually. In addition to dealing with the traditional business, it is quite difficult and complicated to carry out the insurance and housing public accumulation funds system, the state-owned assets management and property registration system, and the zero-based budget system, and combine the budget management with the asset management, which means that the workload is very large. The growth cycle of a skilled financial cadre is usually at least 3 years. However, 
because of the restriction of the establishment, the financial cadre will often be assigned to other posts or released from military service by the time he has consummate skill at financial business, causing the phenomenon of not enough trained younger financial cadres to take over from older experts. The development and implementation of the SOP in financial management can categorize the specific business, provide standard for the complicated and heavy practical work, and make newcomers quickly master the specific operational methods, thus relieving the contradiction between the increasingly heavy financial task and the relative shortage of high-quality financial personnel.

\section{Preventing Financial Work Risks}

The purpose of making the financial Standard Operating Procedure is to better implement all the financial laws and regulations which means to handle the financial work based on the superior laws and regulations and consider all the financial risk factors comprehensively [3]. Firstly, the SOP is an extension of the superior laws and regulations in concrete practice, which is only inferior to laws and regulations and has the effect of regulation on the departments and staff. Secondly, all kinds of risk factors need to be taken into consideration while setting up the SOP in order that the SOP can play the role of "patch". Thirdly, the SOP is located between policies and practice. The application of the SOP can prevent the phenomenon of "the higher authorities have policies while the localities have their countermeasures".

\section{Providing the Basis for the Comprehensive Evaluation of Standardized Management of Financial Business}

At present, the standardized management of military financial work has yet to be improved. Firstly, the comprehensive evaluation standard of financial standardized management is still not unified. Secondly, the comprehensive evaluation method of financial standardized management is still not perfect, the departments "fighting the enemy separately". Thirdly, the comprehensive evaluation mechanism of financial standardized management is still not integrated. The financial Standard Operating Procedure has the function of standardizing and guiding on specific financial business, as a result, it can also be used as an important reference for evaluating the standardized management of military finance.

\section{THE CONCEPTION OF THE APPLICATION OF THE}

\section{STANDARD OPERATING PROCEDURE IN MILITARY FINANCIAL}

\section{MANAGEMENT}

By means of the application of the SOP, the scientific and perfect military financial management system should be set up aimed at specific business so as to define the working process, improve the organization and handover path among working procedures, thus effectively improve the quality and efficiency of work.

\section{A. Making Clear the Position}

The SOP of military finance should be positioned between the superior laws and regulations system composed of laws, regulations, rules, and systems issued by the Party, the state, and the army and the financial business of all the departments, playing the role of a bridge. On the one hand, the rules and regulations can be carried out with a higher standard; on the other hand, the actual operation process of financial work can be standardized in a higher quality.

\section{B. Working out the Authority}

The financial departments at all levels should classify the financial tasks into sorts strictly according to the national and military rules and regulations, carefully formulate the SOP in close connection with the actual situation and taking all the risk factors into account, and carry out the SOP after being reviewed and approved by the superior departments. Unlike the financial laws which are made by the Central Military Commission and the financial departments of the general headquarters and implemented by the army, the financial Standard Operating Procedure is formulated by the departments, enhancing the applicability of its own. Since the SOP is reviewed and approved by the superior financial departments, the requirement of compliance with the rules and regulations is ensured.

\section{Making Definite the Scope of Application}

On the one hand, the financial decision-making behavior should be easily standardized. The system of financial transactions conducted by the Party committee is a fine tradition of our army, the basic principle of financial work, and an important guarantee of the implementation of the financial laws and the construction of the army. It has been proved by the practice that this system has relatively high superiority in financial decision-making, while some problems also exists. Firstly, the majority of the Party committee are military and political cadres. Influenced by the professional and post experience, leaders with high level of financial management is relatively deficient, being the bottleneck that restricts the development of the Party committee's financial management. secondly, due to the Chinese historical culture of "man rules everything", the system of financial transactions conducted by the Party committee often evolves into the situation that some leaders with strong personality decides everything. The above adverse factors will easily lead to the failure of financial decisions. The application of the SOP into financial decision-making can to further highlight the role of the Party committee and laws and regulations, reduce the space of "illegal manipulation" of some leaders, so that improve the financial decision-making level of the Party committee. Generally speaking, a scientific decision-making process should include four basic steps. The first step is raising the questions and identifying the goals. The second one is formulating the feasible plans. The third one is evaluating and optimizing the programs. The last one is the implementation and feedback of the programs. The military financial Standard Operating Procedure should be worked out and carried out thoroughly based on the scientific decisionmaking procedures and combined with the financial regulations and the actual situation to realize the standardization of financial decision-making. 
On the other hand, the practical work of the financial departments should be easily standardized. The practical work of the financial departments has the characteristics of strong policy, miscellaneous business type, heavy workload, high technique and close relationship with the interests of officers and soldiers, having high requirements of the comprehensive qualities, the professional skills and the experience of the financial cadres. According to the actual situation of the army, the financial cadres will have great difficulty in mastering all kinds of practical skills if they don't work for two to three years, even if they are graduates in military finance. Therefore, it's of significance to develop and implement the SOP in the concrete practice of the financial departments. Firstly, new hands can grasp the specific operation skills and experience in a relatively short period of time and the overall business management level can be ensured. Secondly, various types of business work can be standardized to a higher level. The application of the SOP has been highly respected and has achieved good effects in the financial management of local enterprises, so it's a good idea for the army to apply the SOP to the practices of funds management, accounting, auditing, wages and welfare, and insurance and housing.

\section{PROBLEMS THAT SHOULD BE PAID ATTENTION TO IN THE APPLICATION OF THE STANDARD OPERATING PROCEDURE IN MILITARY FINANCE}

The application of the Standard Operating Procedure to financial management is not simply based on experience or the copy of others' procedures, but carry out process analysis and action optimization on the basis of the researching methods of industrial and engineering profession.

\section{A. Dealing Properly with the Relationship Between Compliance with Laws and Regulations and Applicability}

Compliance with laws and regulations refers to the compliance of the SOP with the financial rules and regulations made and issued by the state and the army which means the slightest discount is not allowed. Applicability refers to the achievable SOP under the premise of compliance and pointing at certain business. While the SOP is formulated by the financial departments at all levels, two inclinations should be avoided. Firstly, compliance is overemphasized while applicability is ignored. Undoubtedly, compliance with rules and regulations is the prerequisite for the SOP. If compliance is too much emphasized, while applicability is taken slightly, problems such as waste of management resources and low work efficiency will by easily caused. Secondly, applicability is overemphasized while compliance is neglected. If the financial work is only aimed at saving troubles, simplifying the necessary work procedures and avoiding the restriction of laws and regulations, real or potential risks will be certainly caused to the financial work.

\section{B. Balancing Between Standardized Execution and Flexible Management}

There is a certain common point between military financial work and local financial work, that is both of them needs standardized and scientific management, which is also the logical starting point of the application of the financial
Standard Operating Procedure in the army [4]. But military financial work is military in substance and for the wars, and undertakes complicated logistic tasks. Confronted with the complex situation, if the inappropriate SOP is carried out, the opportunity for combat may be missed. Therefore, the implementation of SOP should be attached importance to in peacetime in order to standardize military financial management. The financial departments should contend for the initiative and take flexible action when carry out the tasks.

\section{Laying Emphasis on the Regular Reformulation of the Standard Operating Procedure}

Things are fickle. The financial Standard Operating Procedure should be reformulated and perfected along with the new situations and new problems faced by the financial work, so as to overcome the rigid operation and prevent the deviation of implementing the regulations and policies [5]. When doing the reformulation, things as follows should be laid stress on. Firstly, the financial departments ought to keep up with the times to ensure that the financial SOP synchronize with the financial laws and regulations and military financial reform. Secondly, efficiency factors ought to be taken into account and operation rules should be optimized in order to save management cost under the precondition of standardized implementation of financial laws and regulations.

\section{CONCLUSION}

In this paper, the basic background of the Standard Operating Procedure is introduced, the necessity of applying the Standard Operating Procedure to advance the standardized management of military finance is analyzed, the conception of applying the Standard Operating Procedure to military financial management is put forward, and problems that should be paid attention to in the application of the Standard Operating Procedure in military finance are analyzed. The application of the Standard Operating Procedure to military financial management is necessary and beneficial from the following four aspects:

- The quality and efficiency of military financial work can be easily improved.

- The contradiction between the increasingly heavy financial task and the relative shortage of high-quality financial personnel can be alleviated to some extent.

- The financial work risks can be prevented.

- The basis for the comprehensive evaluation of the standardized management of financial business can be provided.

When applying the Standard Operating Procedure to military financial management, the following points should be attached significant importance to:

- The relationship between compliance with laws and regulations and applicability should be dealt with properly.

- Standardized execution and flexible management should be balanced. 
- The Standard Operating Procedure should be reformulated regularly.

\section{REFERENCES}

[1] Aliah Blackmore. The Myth of the SOP[J]. The Quality Assurance Journal, ,2004, p.22..

[2] Droj Laurentiu. FINANCIAL INDICATORS FOR THE IMPLEMENTATION OF AN EUROPEAN FUNDED INVESTMENT
PROJECT UNDER SOP IEC PROGRAMME â€“ CASE STUDY OF A ROMANIAN SME[J]. Annals of the University of Oradea : Economic Science, 2008, p.75.

[3] Humphrey, Brad. SOPs will bring your company consistent performance[J]. Concrete Contractor, 2011, p.37.

[4] Anup Srivastava. Selling-price estimates in revenue recognition and the usefulness of financial statements[J]. Review of Accounting Studies, 2014, p.82..

[5] Wiegert Richard S,Soliza Joaquin R,Almonte Juan M,Barner Ernest J,Chipman Nathan M,Cortez Renan,Hope Jacques C. Traction splint. Military use: SOP.[J]. JEMS, 2010, p.25. 